\title{
Correction to: Nomenclature report 2019: major histocompatibility complex genes and alleles of great and small ape and old and new world monkey species
}

\author{
Natasja G. de Groot ${ }^{1}$ - Nel Otting ${ }^{1} \cdot$ Giuseppe Maccari $^{2,3} \cdot$ James Robinson $^{3,4} \cdot$ John A. Hammond ${ }^{2}$. \\ Antoine Blancher ${ }^{5,6}$ - Bernard A. P. Lafont ${ }^{7}$ - Lisbeth A. Guethlein ${ }^{8}$ - Emily E. Wroblewski ${ }^{9}$ - Steven G. E. Marsh ${ }^{3,4}$. \\ Takashi Shiina $^{10} \cdot$ Lutz Walter $^{11} \cdot$ Linda Vigilant $^{12} \cdot$ Peter Parham $^{8} \cdot$ David H. O'Connor ${ }^{13} \cdot$ Ronald E. Bontrop ${ }^{1,14}$
}

Published online: 19 November 2019

(C) Springer-Verlag GmbH Germany, part of Springer Nature 2019

\section{Correction to: Immunogenetics}

$$
\text { https://doi.org/10.1007/s00251-019-01132-x }
$$

The original version of this article contained a spelling error in the Acknowledgements regarding the name of the funding organisation supporting GM and JAH. UKRI-BBSCR should have been UKRI-BBSRC, as is now indicated correctly below.

\section{Acknowledgments}

The authors would like to thank R. Wiseman and J. Caskey for their feedback on the manuscript, D. Devine for editing the manuscript, and F. van Hassel for the artwork. This study was supported in part by NIH/NIAID contract number HHSN272201600007C. GM and JAH are supported by the funding from the UKRI-BBSRC awards BB/M011488/1, BBS/E/I/00001710, BBS/E///00007030 and BBS/E/I/00007038.

Publisher's note Springer Nature remains neutral with regard to jurisdictional claims in published maps and institutional affiliations.

This article is part of the Topical Collection on "Nomenclature, databases and bioinformatics in Immunogenetics"

The online version of the original article can be found at https://doi.org/ 10.1007/s00251-019-01132-x

Natasja G. de Groot

groot@bprc.nl; Ipdmhc_nhp@bprc.nl

Nel Otting

Ipdmhc_nhp@bprc.nl

Ronald E. Bontrop

Ipdmhc_nhp@bprc.nl

Extended author information available on the last page of the article 


\section{Affiliations}

Natasja G. de Groot $^{1}$ • Nel Otting ${ }^{1}$ • Giuseppe Maccari ${ }^{2,3}$ • James Robinson ${ }^{3,4}$ • John A. Hammond ${ }^{2}$. Antoine Blancher ${ }^{5,6}$ - Bernard A. P. Lafont ${ }^{7}$ - Lisbeth A. Guethlein ${ }^{8}$ • Emily E. Wroblewski ${ }^{9}$. Steven G. E. Marsh ${ }^{3,4}$. Takashi Shiina $^{10} \cdot$ Lutz Walter $^{11}$ • Linda Vigilant ${ }^{12} \cdot$ Peter Parham $^{8}$ • David H. O'Connor ${ }^{13} \cdot$ Ronald E. Bontrop $^{1,14}$

1 Department of Comparative Genetics and Refinement, Biomedical Primate Research Centre, Lange Kleiweg 161, 2288, GJ

Rijswijk, The Netherlands

2 The Pirbright Institute, Pirbright, Woking, Surrey, UK

3 Anthony Nolan Research Institute, Royal Free Hospital, Pond Street, Hampstead, London NW3 2QG, UK

4 UCL Cancer Institute, University College London, Royal Free Campus, Pond Street, Hampstead, London NW3 2QG, UK

5 Centre de Physiopathologie Toulouse-Purpan (CPTP), Université de Toulouse, Centre National de la Recherche Scientifique (CNRS), Institut National de la Santé et de la Recherche Médicale (Inserm), Université Paul Sabatier (UPS), 31000 Toulouse, France

6 Laboratoire d'Immunologie, CHU de Toulouse, Institut Fédératif de Biologie, Hôpital Purpan, 330 Avenue de Grande Bretagne,

TSA40031, 31059, CEDEX 9 Toulouse, France

7 Viral Immunology Section, National Institute of Allergy and Infectious Diseases, National Institutes of Health, Bethesda, MD 20892, USA
8 Department of Structural Biology and Department of Microbiology and Immunology, Stanford University, Stanford, CA 94305, USA

9 Department of Anthropology, Washington University, St Louis, MO 63130, USA

10 Department of Molecular Life Science, Division of Basic Medical Science and Molecular Medicine, Tokai University School of Medicine, Hiratsuka-shi, Kanagawa, Japan

11 Primate Genetics Laboratory, German Primate Center, Leibniz Institute for Primate Research, 37077 Göttingen, Germany

12 Max Planck Institute for Evolutionary Anthropology, Deutscher Platz 6, 04103 Leipzig, Germany

13 Department of Pathology and Laboratory Medicine, University of Wisconsin-Madison, Madison, WI 53711, USA

14 Theoretical Biology and Bioinformatics, Utrecht University, 3584, CH Utrecht, The Netherlands 